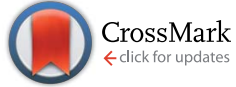

Cite this: J. Anal. At. Spectrom., 2016, 31,1836
Received 29th April 2016

Accepted 29th June 2016

DOI: $10.1039 / \mathrm{c} 6 \mathrm{ja} 00162 \mathrm{a}$

www.rsc.org/jaas

\section{Arsenic containing medium and long chain fatty acids in marine fish oil identified as degradation products using reversed-phase HPLC-ICP-MS/ ESI-MS}

\author{
Éderson R. Pereira, ${ }^{\text {ab }}$ Johannes F. Kopp, ${ }^{\text {b }}$ Andrea Raab, ${ }^{\text {b }}$ Eva M. Krupp, \\ Javier del Campo Menoyo, ${ }^{C}$ Eduardo Carasek, ${ }^{a}$ Bernhard Welz ${ }^{a}$ and Jörg Feldmann ${ }^{\star b}$
}

This study describes the identification and quantification of five new arsenolipids present in raw marine fish oil extracted mainly from Peruvian anchoveta (Engraulis ringens). The arsenolipids accumulated on bentonite, which has been used to clean-up raw fish oils in an industrial process for producing commercial fish oil rich in omega-3 fatty acids. The bentonite, which adsorbed the arsenolipids efficiently from the raw fish oil was extracted with different solvents and subsequently cleaned up by normal phase chromatography, which fractionated all absorbed compounds according to polarity. The arsenic containing fatty acids (AsFA) and arsenic containing hydrocarbons (AsHC) were determined using a separation by reverse phase high performance liquid chromatography coupled online to inductively coupled plasma mass spectrometry (RP-HPLC-ICP-MS) for quantification and simultaneously to electrospray ionization mass spectrometry (ESI-MS) for identification. A mixture of methanol/chloroform $(1: 2 \mathrm{v} / \mathrm{v})$ was sufficient for the extraction of the majority of the adsorbed arsenic species $\left(129 \mu \mathrm{g} \mathrm{g}^{-1} \mathrm{As}\right.$ bentonite). The pre-concentration using the adsorbent with subsequent fractionation made it possible to identify minor arsenolipids especially in the polar methanol fraction. Besides two major arsenic containing hydrocarbons (AsHC332 and AsHC360) three new arsenic containing medium chain fatty acids (As-MCFA) of molecular mass 250, 278, 292 and two new arsenic containing long chain fatty acids (As-LCFA) of mass 306 and 320 could be identified although their concentrations were as low as 0.004 $\mu \mathrm{g} \mathrm{g}^{-1}$ As bentonite. The significance of MCFA is that these compounds usually occur not as free fatty acids but are conjugated to glycerol forming triglycerides. Confirmation of this hypothesis is given in the fact that a methanol extract which was directly analyzed without any clean up procedure did only contain traces of As-LCFA and no As-MCFA but the same concentration of the more inert AsHCs, which are not expected to be conjugated to other organic compounds. This highlights that a successful preconcentration and clean up procedure is essential to determine traces of minor arsenolipids but it does not provide a guarantee for the integrity of all arsenolipid species.

\section{Introduction}

In recent years food supplementation using the natural source fish oil has been of great interest and its production has increased significantly around the world. The main supplementing ingredients are omega- 3 fatty acids, which are not naturally produced by fish but they are accumulated through the food chain via marine organisms and/or microorganisms. ${ }^{1}$ In recent years omega-3 fatty acids have been correlated with the decrease of

\footnotetext{
${ }^{a}$ Departamento de Quimica, Universidade Federal de Santa Catarina, 88040-900 Florianópolis, SC, Brazil

${ }^{b}$ Trace Element Speciation Laboratory (TESLA), Department of Chemistry, University of Aberdeen, Meston Walk, Aberdeen AB243UE, Scotland, UK. E-mail: j.feldmann@abdn. ac.uk; Tel: +44 (0)1224272911

'Golden Omega S.A., Arica, Chile
}

many health problems, such as cardiovascular problems, inflammation, arrhythmic effects, and blood pressure. ${ }^{1-3}$

These positive health effects from fish oil have forced the industries to increase the amount of extracted fish oil and different processes of purification have been adopted in order to eliminate toxic contaminants from the final product. ${ }^{4}$ Among the procedures used to clean-up the fish oil, distillation is generally employed together with some kind of adsorbing agent, such as activated carbon, mussel shells, wood washes and recently, the clay mineral bentonite. ${ }^{5}$ The latter one has interesting properties such as a cation exchange capacity, high surface area, great physical and chemical stability, and surface properties making the bentonite an excellent adsorbent for industrial processes to remove organic compounds such as PCBs and inorganic contaminants. ${ }^{5-7}$ 
Amongst the toxic organometallic contaminants in fish oil are the fat-soluble arsenic species. The so-called arsenolipids are present as dimethylarsinoyl fatty acid (AsFA) or dimethylarsinoyl hydrocarbons (AsHC). Those arsenolipids have only recently been identified in different fish species such as cod, ${ }^{8-11}$ capelin, ${ }^{9,12-14}$ and blue whiting fish. ${ }^{15}$ For analysis these studies have mainly used the partitioning of arsenolipids in a variety of solvents with different polarities (mostly hexane plus aqueous methanol $)^{13-15}$ or successive extraction using hexane/methanol/ dichloromethane, ${ }^{16}$ hexane/aqueous isopropanol, ${ }^{9}$ hexane/ water, ${ }^{8}$ hexane/methanol/chloroform/water. ${ }^{13}$ Concerning the identification and determination of arsenolipids a few studies have used gas chromatography mass spectrometry (GC-MS $)^{13}$ or inductively coupled plasma GC (GC-ICP-MS), ${ }^{17,18}$ microwave induced plasma atomic emission detector GC (GC-MIP-AES), electron ionization-quadrupole mass spectrometry GC (GC-EIqMS), and time-of-flight mass spectrometry GC (GC-TOF-MS). ${ }^{18}$ However, most studies describe the use of reverse phase highperformance liquid chromatography (RP-HPLC) coupled to ICPMS with electrospray ionization mass spectrometry (ESIMS). ${ }^{8,10,14-16,19}$

Although ESI-MS is ideally suited for the identification of arsenolipids using accurate mass, this technique can suffer from co-eluting abundant easy to ionize compounds such as any polar lipid among them phospholipids. The latter may co-elute with the arsenolipids rendering the identification of arsenic species difficult. In order to reduce or eliminate these interferences some approaches have been adopted by Amayo et al. ${ }^{8,16}$ and Arroyo-Abad et al., ${ }^{18,20}$ which used a fractionation via vacuum liquid chromatography (VLC) with a column packed with silica gel and a variety of solvents in order to change the elution strength. Using this strategy the authors could identify $>15$ arsenolipids in total as AsFA and AsHC.

Although the number of strategies to identify arsenolipids is increasing continuously, the knowledge about their molecular identification in different fish is still in its infancy. The reason behind this is that so far the different studies only focused on specific kind of fish, which can only give restricted information regarding the variety of arsenolipids. In contrast the use of pooled samples can provide a panoramic overview about the distribution of arsenolipids present in fish oil while the use of an adsorbent such as bentonite can achieve the pre-concentration of these species allowing for a more detailed study on minor species, since the pre-concentrated sample can be submitted to several cleaning steps in order to isolate the analytes without compromising their detection by mass spectrometry.

In this way, the aim of the project is to identify the general diversity of arsenolipids in marine fish from the Pacific by analyzing the loaded bentonite from a fish oil factory in Chile as well as the characterization of possible novel minor arsenolipids using RP-HPLC coupled simultaneously online to ICPMS and ESI-MS. The focus in this work is the fractionation of arsenic species using several clean-up strategies in order to eliminate any interference for the ESI-MS identification since the phospholipids may elute at the same time as arsenolipids due to the similarity of their polarity.

\section{Materials and methods}

\subsection{Reagents and reference materials}

Ultrapure water with a resistivity of $18 \mathrm{M} \Omega \mathrm{cm}$ was obtained from a model Elga, UK. For the quantification of the species contained in the purified extracts, sodium dimethylarsinate $\left(\mathrm{DMA}^{\mathrm{V}}\right)$ obtained from Acros Organics, UK, was used as a calibration standard. The chemicals used for extraction and purification of the extracts were purchased from Thermo Fisher Scientifics in lab-grade quality. Hydrogen peroxide $\left(\mathrm{H}_{2} \mathrm{O}_{2}, 32 \%\right)$, Fluka (U.K.) and nitric acid (p.a. $\mathrm{HNO}_{3}, 65 \%$ ), Sigma-Aldrich (UK), were employed in all digestion procedures. For the HPLC separation, the eluents methanol (HPLC grade, Rathburn, UK), ammonium carbonate (BDH, UK), and formic acid (mass-spec quality, Fluka) were employed. To ensure the accuracy of the microwave-assisted digestion procedure the CRM DORM-3 (dogfish muscle, certified value of $6.80 \pm 0.64 \mu \mathrm{g} \mathrm{g}^{-1}$ ), was used as reference material and was obtained from National Research Council Canada (NRCC).

\subsection{Samples containing arsenic compounds}

Marine fish oil was collected from Pacific fish using nondiscriminating fishing nets hence provides an ideally pooled sample. But the majority of the fish is Peruvian anchoveta (Engraulis ringens). The oil was extracted using a hydraulic press and an equivalent amount of bentonite (Tonsil $126 \mathrm{FF}$ from Süd-Chemie) was added to the raw oil in order to clean the oil from contaminants. This also leads to a pre-concentration of the contaminants on the bentonite which was then separated from the cleaned oil and stored. All processes described so far were performed according to the extraction and purification of marine fish oil by Golden Omega S.A. Company (Arica, Chile). The adsorbent bentonite, which was separated and stored in a glass bottle, was transferred to the laboratory for subsequent extraction and further sample preparation. The samples were kept at $4{ }^{\circ} \mathrm{C}$ at all times when not handled and the total time between the collected of the material and extraction of the species was shorter than one week.

\subsection{Sequential extraction of arsenic compounds}

Approximately $5 \mathrm{~g}$ of sample were extracted using hexane (50 mL), followed by $60 \mathrm{~mL}$ of methanol/chloroform $(1: 2 \mathrm{v} / \mathrm{v})$, $50 \mathrm{~mL}$ of methanol, and $50 \mathrm{~mL}$ of ultrapure water. All phases were stirred at $700 \mathrm{~g}$ for one hour, centrifuged at $3000 \mathrm{~g}$ for $10 \mathrm{~min}$ and subsequently dried. Then, to each extract $1 \mathrm{~mL}$ of $\mathrm{HNO}_{3}$ and $2 \mathrm{~mL}$ of $\mathrm{H}_{2} \mathrm{O}_{2}$ were added and the samples were submitted to a microwave-assisted digestion procedure using a microwave system (Mars-5, CEM, U.K.) with the following stepwise heating program: $5 \mathrm{~min}$ at $50{ }^{\circ} \mathrm{C} ; 5 \mathrm{~min}$ at $75{ }^{\circ} \mathrm{C}$; and $25 \mathrm{~min} 95^{\circ} \mathrm{C}$. The digested samples were diluted using ultrapure water to $30 \mathrm{~mL}$ and the total content of arsenic was determined.

\subsection{Sequential clean-up using silica column}

The methanol/chloroform (1:2 v/v) extract (Section 2.3), was submitted to a series of clean-up steps using a preparative 


\section{Diagram}

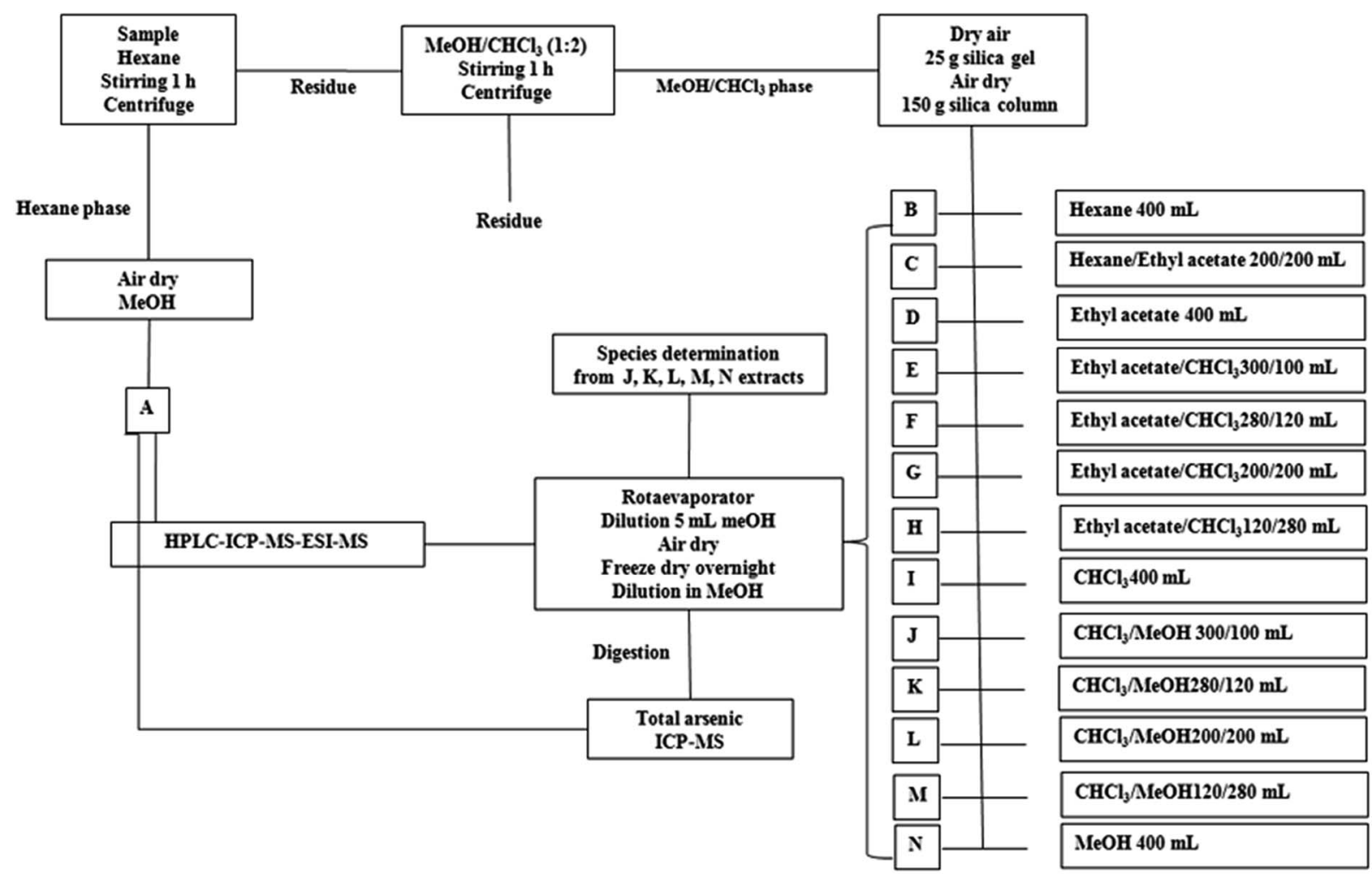

Fig. 1 Flow diagram of the clean-up and fractionation procedure and analytical steps for determination and identification of arsenolipids using RP-HPLC-ICP-MS/ESI-MS.

column which was packed with approximately $150 \mathrm{~g}$ of silica gel (0.063-0.200 mm). Thus, a subsequent elution procedure using hexane, ethyl acetate, chloroform, and methanol as well as different mixtures of them was used for the purpose of a gradual change of eluent polarity (Fig. 1). After that, each extract named here as $\mathrm{B}$ to $\mathrm{N}$ was evaporated to dryness using a rotational evaporator, freeze dried overnight, and diluted in methanol. These resulting fractions were used for the identification of arsenolipids by RP-HPLC-ICP-MS/ESI-MS and total arsenic determination by ICP-MS after microwave-assisted digestion to obtain an arsenic mass balance. The hexane phase was submitted to the same process as described above, however it was just air dried with subsequent dilution using methanol without performing the full clean-up procedure. This is referred to as fraction A.

\subsection{Analytical methodology}

For the separation of arsenolipids a Poroshell EC18 column (2.7 $\mu \mathrm{m}, 4.6 \times 150 \mathrm{~mm})$ was employed using a linear $20 \mathrm{~min}$ gradient from 0 to $100 \%$ methanol $(0.1 \%(\mathrm{v} / \mathrm{v})$ formic acid in water and $0.1 \%(\mathrm{v} / \mathrm{v})$ formic acid in methanol) followed by 20 min $100 \%$ methanol. About $75 \%$ of the eluent from RP-HPLC was directed to ESI-MS while the remaining $25 \%$ were injected into the ICP-MS. An Orbitrap Discovery LTQ (Thermo Scientific, Bremen, Germany) was used as ESI-MS in positive scan-mode (resolution 30 000), while the triple quadrupole 8800 ICP-MS (Agilent Technologies, Wilmington, DE, USA), operating in organic mode (Pt-cones, $10 \%$ option gas $\left(20 \% \mathrm{O}_{2}\right.$ in $\mathrm{Ar}$ ) and $\mathrm{O}_{2}$ as reaction gas $\left.\left(2 \mathrm{~mL} \mathrm{~min}^{-1}\right)\right)$, was applied in all measurements.

Arsenic monitoring was performed using the oxygen mode. While Q1 was set on to $m / z 75$, Q2 was set to $m / z 91$ for the detection of ${ }^{75} \mathrm{As}^{16} \mathrm{O}^{+}$. Phosphate and sulfur compounds were also monitored. For phosphorous and sulfur the Q1 was set to $\mathrm{m} / \mathrm{z} 31$ and 32 respectively. Q2 was set accordingly to monitor the oxygen species on $m / z 47$ as ${ }^{31} \mathrm{P}^{16} \mathrm{O}^{+}$and $m / z 48$ as ${ }^{32} \mathrm{~S}^{16} \mathrm{O}^{+}$. Germanium $(\mathrm{m} / \mathrm{z} 72)$ was used as the continuous internal standard added post column, and measured under the same conditions as ${ }^{72} \mathrm{Ge}^{+}$(Q1 and Q2 set to $m / z 72$ ).

Quantification was carried out against standard solutions of $\mathrm{DMA}^{\mathrm{v}}$. For this, the response factor $\left(\mathrm{As}_{\mathrm{rf}}\right)$ was determined using the approach described by Amayo et al. ${ }^{16}$ and Sele et al. ${ }^{21}$ The procedure involves the use of post-column injection of standard $\left({ }^{75} \mathrm{As}\right.$ as DMA $)$ and internal standard $\left({ }^{72} \mathrm{Ge}\right)$ while measuring a blank sample in order to compensate the time-resolved variation in the arsenic response along the gradient induced by the increase of methanol which leads to a time-dependent change in the signal due to carbon-enhancement. ${ }^{16}$ In this way, the concentrations of the arsenic-containing compounds were determined using the $\mathrm{As}_{\mathrm{rf}}$ for the peaks and the use of the calibration curves established from DMA as standards. For mass balance purposes, each extract was submitted to 
a digestion procedure in order to evaluate the recovery of each peak from the HPLC procedure.

\section{Results and discussion}

The studies involving strategies for the extraction and identification of arsenolipids have been focusing on arsenic containing long chain fatty acids (As-LCFA), which have been found in different biological matrix like brown alga, ${ }^{22,23}$ fish meal, ${ }^{16}$ fresh cod liver ${ }^{\mathbf{2 0}}$ and oil fish. ${ }^{\mathbf{1 0 , 1 1 , 1 4 , 2 1}}$ However, arsenic containing MCFA (As-MCFA) have not been detected in these studies probably due their low concentration. Here, we are showing the identification and quantification of two new As-MCFA and three new As-LCFA by RP-HPLC-ICP-MS/ESI-MS in an extract from bentonite which was used as adsorbent in a commercial fish oil factory.

\subsection{Total arsenic concentration in extracts from sequential extraction}

Among the different extracts, the methanol/chloroform $(1: 2$ $\mathrm{v} / \mathrm{v}$ ) fraction showed the highest concentration of arsenic after digestion and quantification by ICP-MS $\left(43 \%, 129 \mu \mathrm{g} \mathrm{g}^{-1}\right)$, followed by the extraction residue $\left(34 \%, 102 \mu \mathrm{g} \mathrm{g}^{-1}\right)$, water $(16 \%$, $\left.49 \mu \mathrm{g} \mathrm{g}^{-1}\right)$, methanol $\left(6 \%, 17 \mu \mathrm{g} \mathrm{g}^{-1}\right)$ and hexane with $0.4 \%(1.2$ $\left.\mu \mathrm{g} \mathrm{g}^{-1}\right)$. The strategy using methanol combined with a less polar solvent for extraction of arsenic compounds has been successfully applied by other groups focusing in the extraction of lipids, hydrocarbons and phospholipids. Raab et al. ${ }^{22}$ describe that among different extractants (hexane, $\mathrm{CH}_{2} \mathrm{Cl}_{2} /$ methanol, and methanol) used for extraction of arsenic compounds in brown alga (Saccharina latissima), the $\mathrm{CH}_{2} \mathrm{Cl}_{2} /$ methanol $(2: 1 \mathrm{v} / \mathrm{v})$ mixture was the fraction that showed the highest concentration of arsenic (AsFA and AsHC) as well as arsenic containing phospholipids (AsPL). The same approach was adopted by Amayo et $a l .{ }^{\mathbf{1 6}}$ in the determination of arsenic compounds in fish meal from capelin (Mallotus villosus).

Regarding the concentration found in the extract residue (34\%), it is totally plausible that arsenic could be irreversibly absorbed into the porous structure of the bentonite and was only removed when bentonite was submitted to acid digestion. Bentonite contains a high proportion of Na-montmorillonite $\left[\mathrm{Na}_{0.6}\left[\mathrm{Si}_{7.8} \mathrm{Al}_{0.2}\right]^{\mathrm{IV}}\left[\mathrm{Al}_{3.6} \mathrm{Mg}_{0.4}\right]^{\mathrm{VI}} \mathrm{O}_{20}(\mathrm{OH})_{4}\right.$ (omitting water)], which is a clay mineral that swells in water and endows bentonite with a very low hydraulic conductivity, making the diffusion of it smaller than the one of normal water. ${ }^{6}$ Besides that, cationic arsenic in arsenobetaine or tetramethylarsonium may bind tightly to the bentonite due to their positive charge further hindering the diffusion process. ${ }^{6}$

\subsection{Identification of arsenic compounds after sequential clean-up}

From the total As found in the methanol/chloroform $(1: 2 \mathrm{v} / \mathrm{v})$ fraction, the next step was the identification of arsenic compounds by RP-HPLC-ESI-MS as well as their quantification

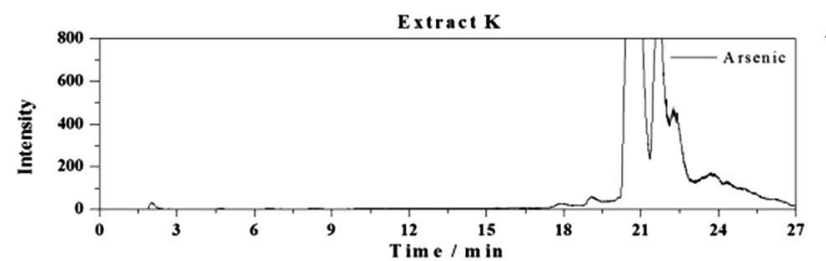

A
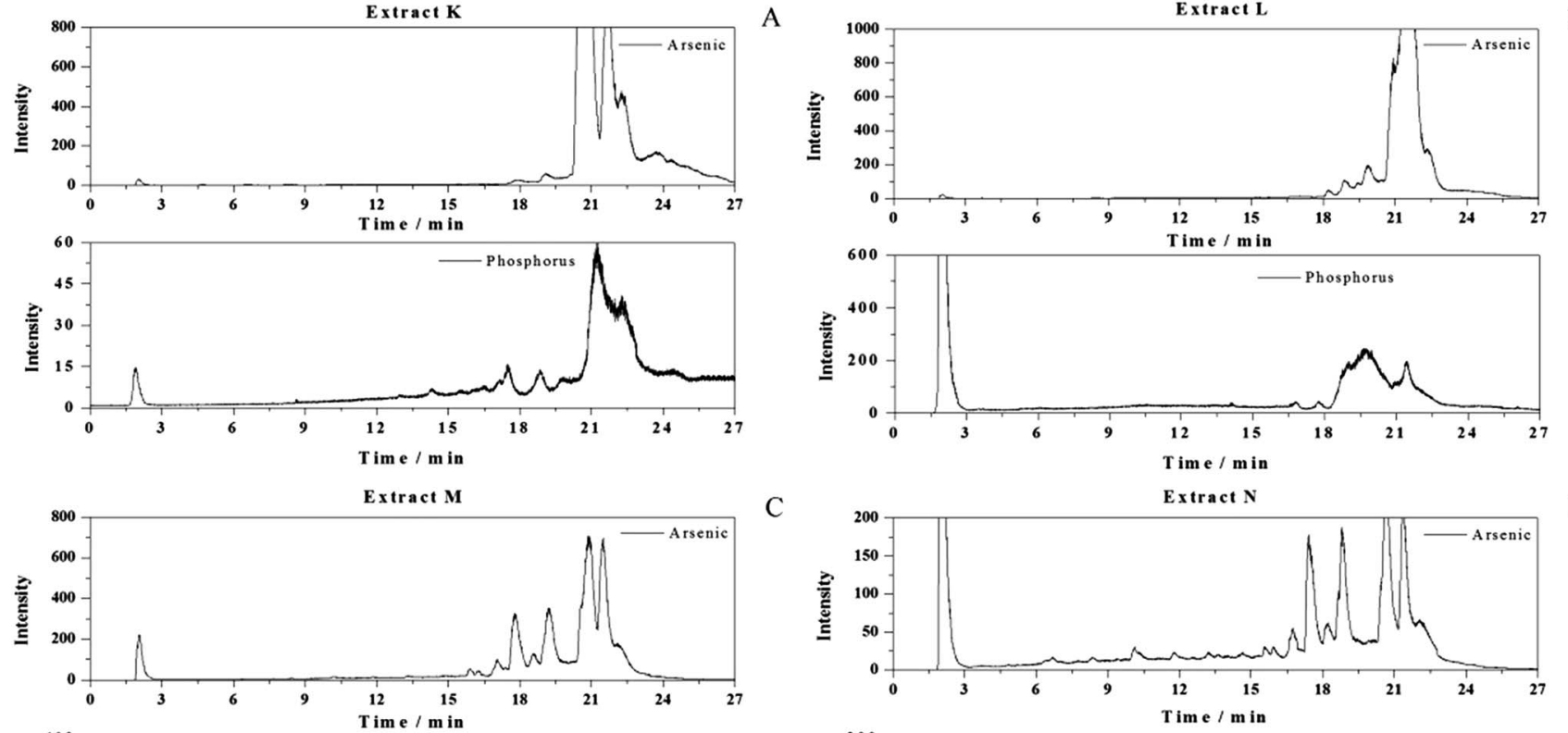

$\mathrm{C}$

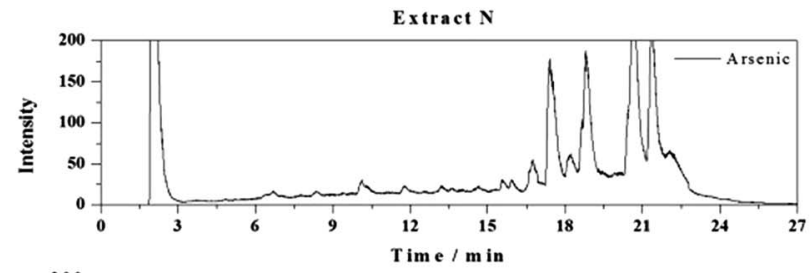

D
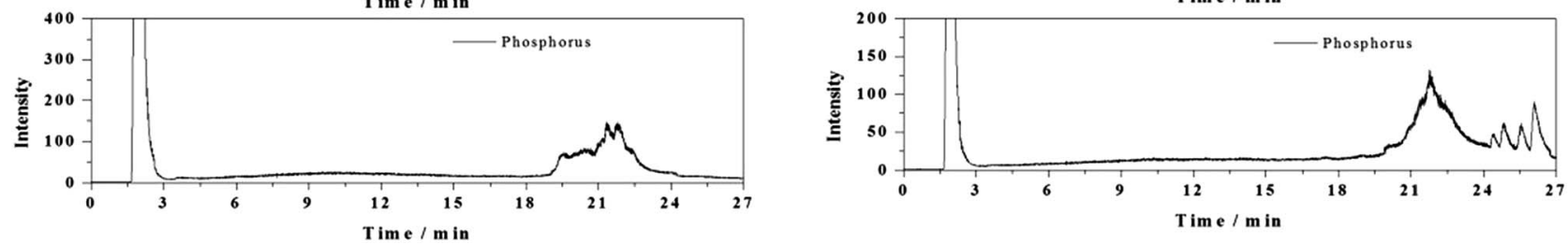

Fig. 2 RP-HPLC-ICP-MS for arsenic and phosphor chromatograms from cleaned fraction $K(A), L(B), M(C)$ and $N(D), u s i n g$ a mixture of chloroform/methanol with proportions of $2: 1(\mathrm{v} / \mathrm{v}), 1: 1(\mathrm{v} / \mathrm{v}) ; 1: 2(\mathrm{v} / \mathrm{v})$ and methanol, respectively. 
by ICP-MS. However, the first results obtained from the extract showed interferences caused by phosphorus containing compounds, which co-eluted with the arsenic compounds in the HPLC separation. It is important to note that while the ICPMS can easily atomize and ionize both phosphorus and arsenic containing compounds quasi-simultaneously, the ESI-source is known to show ionization suppression when easy to ionize compounds reach the electrospray simultaneously with the analytes, especially if one of them is in high abundance. This means that most of the time the compounds of interest will not be detected due to co-eluting matrix components, which are often phospholipids in the case of arsenolipid-analysis because of their similar polarity.

An adaptation of a reported clean-up process was employed using different mixtures of solvents in order to isolate the arsenolipids with maximum efficiency. ${ }^{\mathbf{1 8 , 2 0}}$ Thus, in this study the methanol/chloroform $(1: 2 \mathrm{v} / \mathrm{v})$ extract was submitted to normal-phase clean-up to give fractions (A-N) from eluents of different composition as shown in Section 2.4 for subsequent identification and quantification by ICP-MS/ESI-MS.

Arsenic was only found in more polar fractions from $\mathrm{K}$ (chloroform/methanol, $2: 1 \mathrm{v} / \mathrm{v}$ ) (Fig. 2A) onwards. The detected phosphorus however indicates that parallel to the elution of arsenic compounds also a series of phosphorous containing lipids occurred in these fractions. The phosphorous species distribution changes significantly between extracts $\mathrm{K}-\mathrm{N}$. It is apparent that extract $\mathrm{N}$ shows less co-elution of the minor arsenic species with phosphorous species then in extract $\mathrm{K}$.

The ESI-MS spectra of fractions $\mathrm{M}$ and $\mathrm{N}$ were found indeed less noisier indicating low amounts of organic compounds, the identification of different low abundant AsFA and AsHC could be performed using RP-HPLC-ICP-MS/ESI-MS. The chromatogram in Fig. 3 shows several peaks detected as arsenic in the ICP-MS (U1-U5 and 1-6), with retention times between 5 and 10 min for extract N. From ESI-MS fragmentation, seven known
AsFA and two AsHC (peaks 7 and 8) were identified by the arsenic detection in ICP-MS and the simultaneous detection of the protonated molecular peak in the ESI-MS. The molecular formulae were determined by the accurate masses of the protonated molecular peaks co-eluting with the arsenic peaks of the ICP-MS and with the aid of characteristic product ions (MS/ MS, Table 1). Additionally five so-far unknown AsFA (U1 to U5) could be identified in the same way.

The newly identified AsFA were identified as arsenic containing MCFA and LCFA and have not been reported in fish oil or anywhere else up to now. The results show the presence of five AsFA with the following protonated molecular formulas: $\mathrm{C}_{9} \mathrm{H}_{19} \mathrm{AsO}_{3}$ (calculated for $[\mathrm{M}+\mathrm{H}]^{+} 251.0622$; found 251.0623; $\Delta m$ $=-0.2 \mathrm{ppm}$ ) $; \mathrm{C}_{11} \mathrm{H}_{24} \mathrm{AsO}_{3}$ (calculated for $[\mathrm{M}+\mathrm{H}]^{+}$279.0935; found 279.0932; $\Delta m=-0.4 \mathrm{ppm}$ ); $\mathrm{C}_{12} \mathrm{H}_{26} \mathrm{AsO}_{3}$ (calculated for [M $+\mathrm{H}]^{+}$293.1092; found 293.1087; $\Delta m=-1.7 \mathrm{ppm}$ ); $\mathrm{C}_{13} \mathrm{H}_{28} \mathrm{AsO}_{3}$ (calculated for $[\mathrm{M}+\mathrm{H}]^{+}$307.1248; found 307.1244; $\Delta m=-1.3$ ppm); $\mathrm{C}_{14} \mathrm{H}_{30} \mathrm{AsO}_{3}$ (calculated for $[\mathrm{M}+\mathrm{H}]^{+}$321.1405; found 321.1396; $\Delta m=-2.8 \mathrm{ppm})$. Additionally, the MS/MS function of the orbitrap was able to record the characteristic product ions for the characteristic dimethylarsinoyl moiety confirming the generic structure of the AsFA. Table 1 shows the following product ions after fragmentation of their molecular ions: $\left(\mathrm{m} / \mathrm{z}\right.$ 91: $\mathrm{AsO}^{+}, \mathrm{m} / \mathrm{z}$ 103: $\left(\mathrm{CH}_{2}\right)_{2}=\mathrm{As}^{+} \mathrm{m} / z$ 105: $\left(\mathrm{CH}_{3}\right)_{2} \mathrm{As}^{+}, \mathrm{m} / z$ 123: $\left.\left(\mathrm{CH}_{3}\right)_{2} \mathrm{AsOH}_{2}^{+}\right)$. The five new proposed AsFA structures identified using ESI-MS are shown in Fig. 4. Besides, six arsenic fatty acids that have been reported by other authors were found: AsFA 264, ${ }^{19,20}$ AsFA 334, ${ }^{\mathbf{8 , 1 0}}$ AsFA $348 ;^{8}$ AsFA $362 ;^{\mathbf{8 , 1 0 , 1 6 , 2 0}}$ AsFA $388 ;^{\mathbf{1 0 , 1 9 , 2 0}}$ and AsFA 390. ${ }^{\mathbf{8 1 0 , 2 0}}$

In terms of quantification the most abundant arsenolipids are peaks 7 and 8 in Fig. 3 correspond to $\mathrm{C}_{17} \mathrm{H}_{38} \mathrm{AsO}$ (molecular mass of 332) and $\mathrm{C}_{19} \mathrm{H}_{42} \mathrm{AsO}$ (molecular mass of 360), respectively, which are AsHC that have been identified by others authors as well. .14,20,22 $^{\text {(14, }}$

The saturated hydrocarbons 332 (dimethyl(pentadecyl) arsine oxide) and 360 (heptadecyldimethylarsine)oxide showed

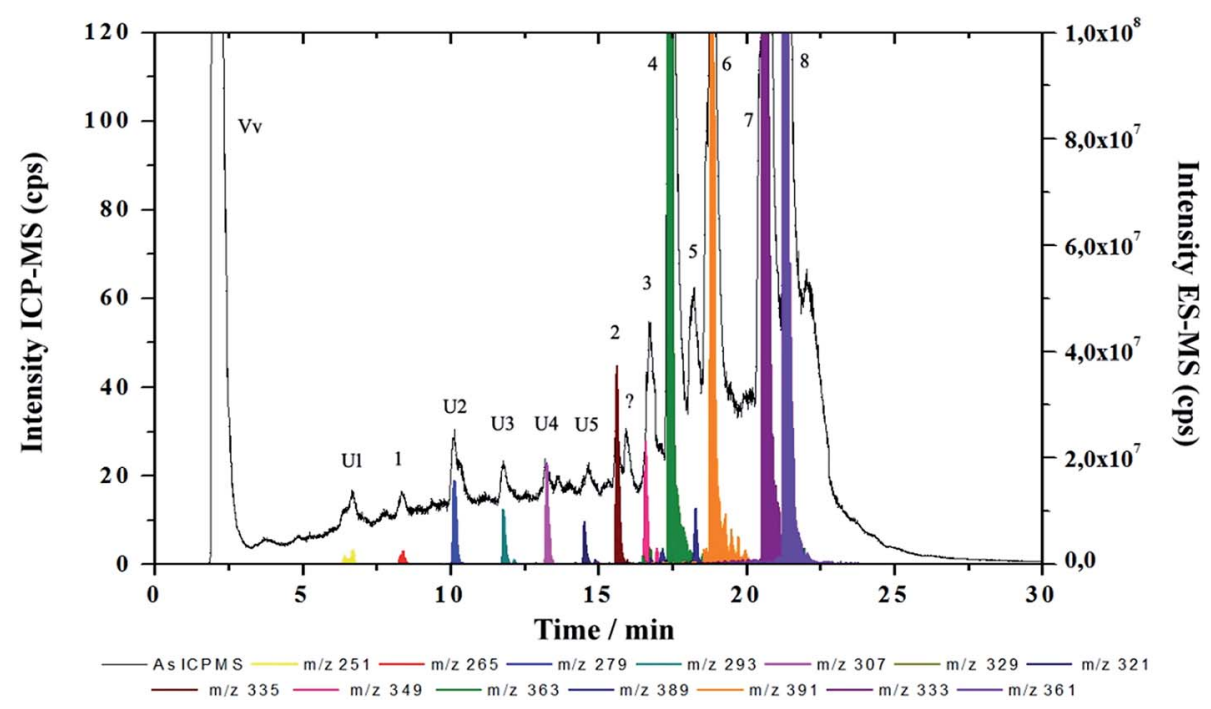

Fig. 3 RP-HPLC-ICP-MS/ESI-MS chromatograms obtained from clean-up fraction N showing all peaks detected by ICP-MS overlaid with extracted mass chromatograms detected by ESI-MS. The number of the peaks correspond to those listed in Table 1. 
Table 1 Molecular formula, experimental and calculated accurate mass, relative error and percentage recovery of the arsenolipids identified by RP-HPLC-ICP-MS/ESI-MS in positive mode $[\mathrm{M}+\mathrm{H}]^{+}$from extract N. $R(\%)$ give the $\%$ of this arsenic species of the total arsenic in the extract

\begin{tabular}{|c|c|c|c|c|c|c|}
\hline Compound & Ion formula & $m / z \exp$ & $m / z$ calc & Product ion & $\Delta_{m / z}(\mathrm{ppm})$ & $R / \%$ \\
\hline U1 & $\mathrm{C}_{9} \mathrm{H}_{19} \mathrm{AsO}_{3}$ & 251.0622 & 251.0623 & $\begin{array}{l}104.9680 \\
102.9521 \\
122.9782\end{array}$ & -0.2 & 0.05 \\
\hline 1 & $\mathrm{C}_{10} \mathrm{H}_{22} \mathrm{As} \mathrm{O}_{3}$ & 265.0778 & 265.0779 & $\begin{array}{l}104.9680 \\
122.9782\end{array}$ & -0.4 & 0.07 \\
\hline $\mathrm{U} 2$ & $\mathrm{C}_{11} \mathrm{H}_{24} \mathrm{AsO}_{3}$ & 279.0932 & 279.0935 & $\begin{array}{r}90.9154 \\
102.9521 \\
104.9680 \\
122.9782\end{array}$ & -1.1 & 0.18 \\
\hline U3 & $\mathrm{C}_{12} \mathrm{H}_{26} \mathrm{AsO}_{3}$ & 293.1087 & 293.1092 & $\begin{array}{r}90.9154 \\
102.9521 \\
104.9680 \\
122.9782\end{array}$ & -1.7 & 0.08 \\
\hline $\mathrm{U} 4$ & $\mathrm{C}_{13} \mathrm{H}_{28} \mathrm{AsO}_{3}$ & 307.1244 & 307.1248 & $\begin{array}{r}90.9154 \\
102.9521 \\
104.9680 \\
122.9782\end{array}$ & -1.3 & 0.07 \\
\hline U5 & $\mathrm{C}_{14} \mathrm{H}_{30} \mathrm{AsO}_{3}$ & 321.1396 & 321.1405 & $\begin{array}{l}102.9521 \\
104.9680 \\
122.9782\end{array}$ & -2.8 & 0.09 \\
\hline 2 & $\mathrm{C}_{15} \mathrm{H}_{32} \mathrm{AsO}_{3}$ & 335.1555 & 335.1561 & $\begin{array}{l}102.9521 \\
104.9680 \\
122.9782\end{array}$ & -1.8 & 0.10 \\
\hline 3 & $\mathrm{C}_{16} \mathrm{H}_{34} \mathrm{AsO}_{3}$ & 349.1710 & 349.1718 & $\begin{array}{l}102.9521 \\
104.9680 \\
122.9782\end{array}$ & -2.3 & 0.6 \\
\hline 4 & $\mathrm{C}_{17} \mathrm{H}_{36} \mathrm{AsO}_{3}$ & 363.1868 & 363.1874 & $\begin{array}{l}102.9521 \\
104.9680 \\
122.9782\end{array}$ & -1.6 & 3.9 \\
\hline 5 & $\mathrm{C}_{19} \mathrm{H}_{38} \mathrm{AsO}_{3}$ & 389.2020 & 389.2031 & $\begin{array}{l}104.9680 \\
122.9782\end{array}$ & -2.8 & 1.1 \\
\hline 6 & $\mathrm{C}_{19} \mathrm{H}_{40} \mathrm{AsO}_{3}$ & 391.2177 & 391.2187 & $\begin{array}{l}104.9680 \\
122.9782\end{array}$ & -2.5 & 4.0 \\
\hline 7 & $\mathrm{C}_{17} \mathrm{H}_{38} \mathrm{AsO}$ & 333.2122 & 333.2133 & $\begin{array}{r}90.9154 \\
102.9521 \\
104.9680 \\
122.9782\end{array}$ & -3.3 & 48 \\
\hline 8 & $\mathrm{C}_{19} \mathrm{H}_{42} \mathrm{AsO}$ & 361.2435 & 361.2446 & $\begin{array}{r}90.9154 \\
102.9521 \\
104.9680 \\
122.9782\end{array}$ & -3.0 & 20 \\
\hline Void vol. & - & - & - & - & - & 6.5 \\
\hline
\end{tabular}

the highest abundance among the arsenolipids found in this cleaned up bentonite extract from marine fish oil $(48 \%$ and $20 \%$, respectively). Other abundant compounds were the LCFAs AsFA (390) and AsFA (362). Both had an abundance of about 4\% each. The MCFAs were much less abundant.

\subsection{Quantification of arsenolipids by HPLC-ICP-MS}

Total arsenic was determined in all fractions from the silica clean-up procedure (see Fig. 1) prior to RP-HPLC separation. The column recovery of arsenic for extracts $\mathrm{K}-\mathrm{N}$ was between $89 \%$ and $95 \%$ when comparing the sum of the concentration of the individual peaks from each extract to the total concentration found in each fraction after microwave-assisted digestion. The highest concentrations were found in the $\mathrm{K}$ and L extracts, with
$25.3 \pm 1.9 \mu \mathrm{g} \mathrm{g}^{-1}$ and $22.1 \pm 0.2 \mu \mathrm{g} \mathrm{g}^{-1}$, respectively. These high concentrations were caused mainly by AsHC 332 and AsHC 360 which have a high affinity to $\mathrm{CHCl}_{3} / \mathrm{MeOH}(1: 1 \mathrm{v} / \mathrm{v})$. The recovery using the digestion procedure from the extract $\mathrm{A}-\mathrm{N}$ was calculated as $\Sigma_{\text {digestion }}=77.8 \mu \mathrm{g} \mathrm{g}^{-1}$ while the recovery found from of the sum of peaks A-N using the speciation procedure was calculated as $\Sigma_{\text {speciation }}=68.7 \mu \mathrm{g} \mathrm{g}^{-1}$, which gives a mass recovery for arsenic of $88 \%$ between both procedures. This is nearly quantitative and shows that the loss of arsenic has been minimal during the extraction, clean-up, and speciation steps.

However, it should be pointed out that only due to the preconcentration and the clean-up of the extracts using bentonite and a silica column it was possible to detect, quantify and most importantly identify very low concentrations of arsenic compounds from the bentonite samples. For instance, the 
U1<smiles>CC(=O)CCCCCCC(=O)O</smiles>

$\mathrm{U} 2$

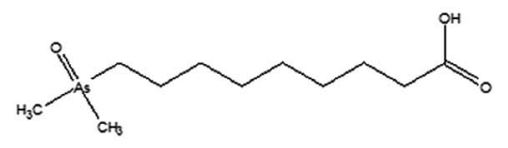

U3<smiles>C[SH](C)(=O)CCCCCCCCCC(=O)O</smiles>
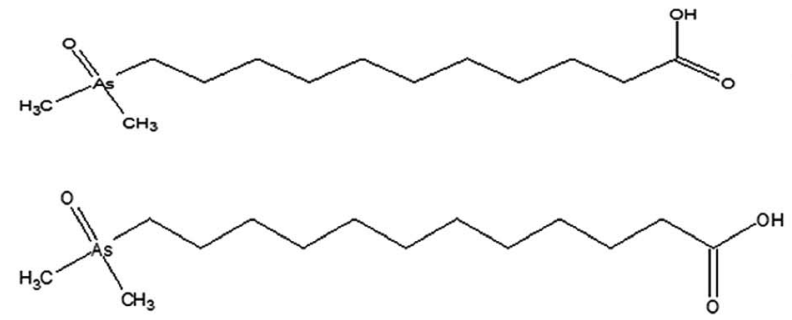

Fig. 4 Proposed molecular structures and theoretical molecular mass $[\mathrm{M}+\mathrm{H}]^{+}$of the unknown AsFA (U1-U5) identified in the most polar fraction of the chloroform/methanol extract of the bentonite adsorbent after the clean-up.

concentrations of AsFAs 250, 264, 278, 292, 306, 320, 334 and 348 in the bentonite samples from in extract $\mathrm{N}$ were only between 0.0043 and $0.0526 \mu \mathrm{g} \mathrm{g}^{-1}$ As bentonite, while the major arsenolipids AsFA 362, 388, 390 and AsHC 333, 361 showed concentrations between 0.3 and $4.2 \mu \mathrm{g} \mathrm{g}^{-1}$. That means that traces of As-MCFA could not only be detected but also quantified. The original concentration in the fish oil can however not be established here, since the amount of fish oil used to preconcentrate on the bentonite during the industrial process is unknown, although the total arsenic concentration in the raw fish oil from this factory has recently been reported to be around $10 \mu \mathrm{g} \mathrm{g}^{-1}$ As fish oil. ${ }^{4}$ Hence, the As-MCFA will be in the lower $n g \mathrm{~g}^{-1}$ concentration range in the fish oil.

To verify the quantitative results from the microwave-assisted digestion procedure the CRM DORM-3 (certified value of $6.80 \pm 0.64 \mu \mathrm{g} \mathrm{g}^{-1}$ ), was digested alongside the samples using the same digestion procedure giving a concentration of $6.97 \pm$ $0.12 \mu \mathrm{g} \mathrm{g}^{-1}$ (recovery of $102 \%, n=5$ ). A bentonite blank showed a concentration below the LOQ of the method $\left(<0.10 \mu \mathrm{g} \mathrm{g}^{-1}, 3 \sigma\right.$ criterion).

\subsection{Integrity of arsenolipids}

Generally the AsFA arsenolipids class showed the highest diversity in their speciation, although quantitatively more AsHC were determined in the bentonite extracts. AsFA represents fatty acids with a molecular structure composed of 12 or more carbon atoms in its chain. The chain can be saturated or unsaturated. Among them, the most prevalent ones are the 13(dimethylarsoryl)tridecanoic acid $\left(\mathrm{C}_{15} \mathrm{H}_{32} \mathrm{AsO}_{3}-\right.$ mass 334$)$ found by Arroyo-Abad et al. ${ }^{20}$ and Rumpler et al. ${ }^{10}$ in fresh cod liver and cod-liver oil, respectively; 15-(dimethylarsoryl)pentadecanoic acid $\left(\mathrm{C}_{17} \mathrm{H}_{36} \mathrm{AsO}_{3}\right.$ - mass 362$)$ has been identified in cod-liver oil, ${ }^{\mathbf{8}, 10}$ herring fillet (Clupea harengus) ${ }^{\mathbf{1 9}}$ and capelin oil (Mallotus villosus), ${ }^{\mathbf{1 4}}$ and 17-(dimethylarsoryl)heptadecanoic acid $\left(\mathrm{C}_{19} \mathrm{H}_{40} \mathrm{AsO}_{3}-\right.$ mass 390) which has been found in fish oil (Micromesistius poutassou) ${ }^{15}$ and fresh cod liver. ${ }^{20}$ It seems that some AsFA are common while others are very specific for the type of fish.

Our success in identifying five new AsFA in fish-oil can be explained based on three strategic points in our approach. The first one is not having selected one specific species of fish for the extraction of an oil sample. Hence, it can be expected that a higher diversity of AsFA can be found, since different species of fish may have a different metabolism and accumulate different AsFAs.

The second and more important point is the systematic sequential clean-up and fractionation step used for the separation of phospholipids (arsenic or not) from the arsenic fatty acids using preparative column chromatography on silica gel

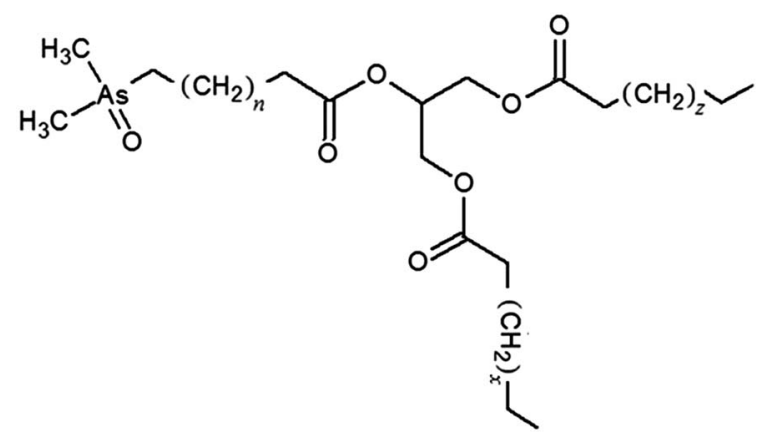

Fig. 5 Proposed structure of an arsenic containing medium chain fatty acid containing triglyceride. The subscript $n, z$ and $x$ represent the number of carbons. 


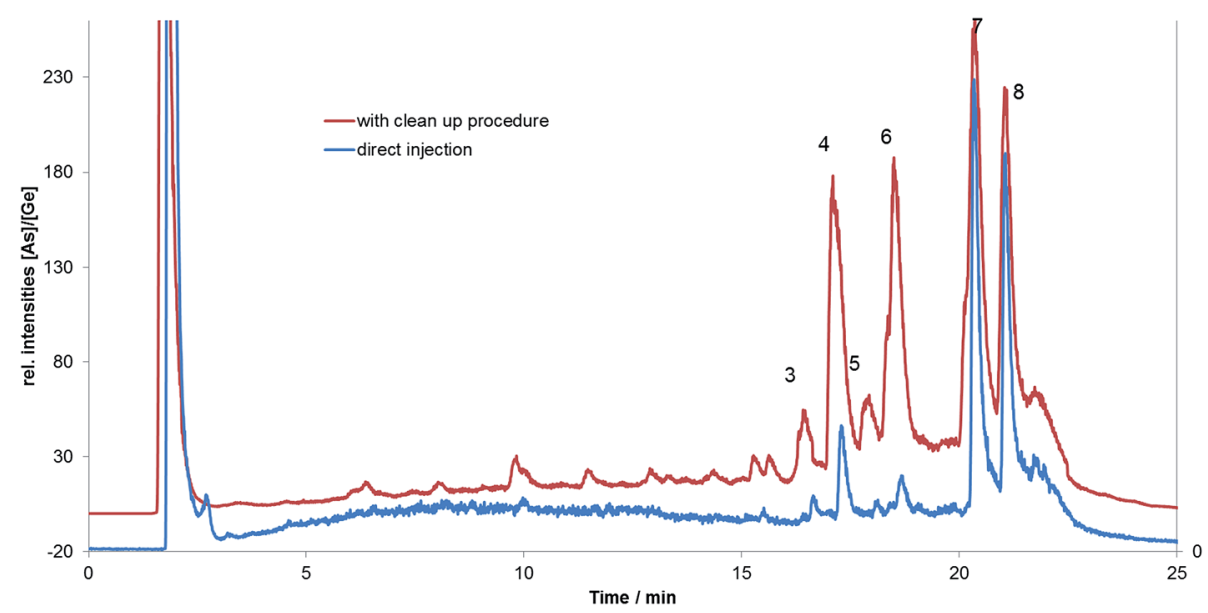

Fig. $6 \mathrm{HPLC}-\mathrm{ICP}-\mathrm{MS}$ chromatogram of bentonite $(2 \mathrm{~g}$ of sample) extracted from of $5 \mathrm{~mL}$ of methanol, shaking for $2 \mathrm{~min}$ and immediately injected without clean-up in RP-HPLC-ICP-MS, compared to the methanol fraction after clean up (extract N). The number of the peaks are the same as in Fig. 3.

(see in Section 3.2). This clearly made it possible to identify small concentrations of AsFA.

However, the occurrence of free MCFAs is unexpected, since most MCFA are normally present as triglycerides and this may hold also for the As-MCFA. These relative polar arsenolipids (much more polar than the detected AsHC) were extracted in the methanol/chloroform $(1: 2 \mathrm{v} / \mathrm{v})$ extract (a medium-polar phase) and then only showed up after the clean-up steps in the most polar methanol fraction (extract $\mathrm{N}$ ). This is a strong indication that the As-MCFA were extracted in a different form, which in this case, might be arsenic containing triglycerides as suggested also by Taleshi et al. ${ }^{15}$ (Fig. 5).

Recently, it has been found that As-LCFA can be conjugated to phosphatidylcholine and form arsenic containing phospholipids. ${ }^{24}$ We propose that the hydrolysation of the As-MCFA and As-LCFA from more non-polar lipids was a consequence of the fractionation procedure using a silica column and a gradient of solvents with increasing elution strength. Otherwise the free AsFA would be extracted in a more polar phase (methanol) and not by using methanol/chloroform $(1: 2 \mathrm{v} / \mathrm{v})$ mixture in the initial sequential extraction without clean-up. To prove this, Fig. 6 shows two methanol fractions, one generated by direct extraction without the clean-up steps and the other the methanol fraction after the use of the normal phase chromatography (extract N). It is apparent that the AsHC occurred in both methanol fractions in a similar ratio while the detected AsFA are in far lower abundance in the methanol fraction with was directly analysed without a clean-up. AsHC would not be expected to be conjugate to other lipid moieties and hence the AsHC species show the same abundance in both methanol fractions (Fig. 6). This illustrates that the As-MCFA and As-LCFA were generated during the sample clean-up rather than the chromatographic separation and their precursors could be As-FA triglycerides or potentially As-FA containing phospholipids or even sphingomyelins. Hence, the cleanup procedure provides the opportunity to identify traces of arsenolipid species but it cannot guarantee the integrity of the arsenolipid speciation.

\subsection{Toxicological implications}

The major arsenolipids found to be absorbed on the bentonite from marine fish were the AsHC 360 and 332. These compounds were tested for their toxicological potency by using cell cultures and found to be as cytotoxic as arsenite, ${ }^{25}$ while the As-LCFA have shown significant toxicity but to a far less extent than the AsHC, ${ }^{26}$ while As-MCFA have not been tested so far.

The information highlighted here can be essential to understand the chemistry of As-MCFA in the human body since triglycerides, when ingested, are rapidly hydrolyzed and the AsMCFA can enter the body metabolism route as free fatty acid. In contrast to LCFA, MCFA show lower viscosity, with high absorption and solubility in biological processes since they are easily hydrolyzed by pancreatic lipases. ${ }^{27}$ Hence, this is also expected from the As-MCFA containing lipids during ingestion.

\section{Conclusions}

The work presents the identification and quantification of thirteen lipid soluble organic arsenic compounds using HPLCICP-MS/ESI-MS. Among the identified molecules were two arsenic containing hydrocarbons while the other ones were arsenic containing fatty acids. Of the arsenic containing fatty acids, the medium chain fatty acids with masses of 250 and 278 and long chain fatty acids with masses of 292, 306 and 320 have been identified for the first time in marine fish oil which has been pre-concentrated using bentonite as adsorbent. For the success in the identification using electrospray ionization, a clean-up strategy using preparative normal phase chromatography on silica gel has been adopted for eliminating other lipophilic compounds such as phospholipids which could coeluted together with the arsenic containing fatty acids and hydrocarbons. The high concentration of arsenic in the methanol/chloroform phase $\left(129 \mu \mathrm{g} \mathrm{g}^{-1}, 43 \%\right)$ as well as the identification of medium chain fatty acids in them awakens a new interest in the presence of arsenic containing triglyceride or 
arsenic containing phosphatidylcholine species in marine fish oil. Hence, it provides an interesting speculation about the biosynthesis of arsenic containing lipids, especially due to their ease to hydrolyze compared to LCFA, which may show different routes of absorption in biological systems. However, the analytical challenge remains to identify non-polar arsenolipids without hydrolysis.

\section{Acknowledgements}

The authors are grateful to Conselho Nacional de Desenvolvimento Científico e Tecnológico (CNPq), and Coordenação de Aperfeiçoamento de Pessoal de Nível Superior (CAPES) for financial support and scholarships. The present research was mostly financed through Project no. CNPq 406877/2013-0. Our thanks to Golden omega that provided suitable bentonite samples and to University of Aberdeen for total support and collaboration.

\section{References}

1 C. J. Lavie, R. V. Milani, M. R. Mehra and H. O. Ventura, Omega-3 Polyunsaturated Fatty Acids and Cardiovascular Diseases, J. Am. Coll. Cardiol., 2009, 54, 585-594.

2 P. Nestel, P. Clifton, D. Colquhoun, M. Noakes, T. A. Mori, D. Sullivan and B. Thomas, Indications for Omega-3 Long Chain Polyunsaturated Fatty Acid in the Prevention and Treatment of Cardiovascular Disease, Heart, Lung Circ., 2015, 24, 769-779.

3 A. P. DeFilippis and L. S. Sperling, Understanding omega-3's, Am. Heart J., 2006, 151, 564-570.

4 É. R. Pereira, T. S. de Almeida, D. L. G. Borges, E. Carasek, B. Welz, J. Feldmann and J. d. C. Menoyo, Investigation of chemical modifiers for the direct determination of arsenic in fish oil using high-resolution continuum source graphite furnace atomic absorption spectrometry, Talanta, 2016, 150, 142-147.

5 C. A. J. Appelo and P. Oy, A Review of Porosity and Diffusion in Bentonite, 2013.

6 I. C. Bourg, A. C. M. Bourg and G. Sposito, Modeling diffusion and adsorption in compacted bentonite: a critical review, J. Contam. Hydrol., 2003, 61, 293-302.

7 A. S. Bhatt, P. L. Sakaria, M. Vasudevan, R. R. Pawar, N. Sudheesh, H. C. Bajaj and H. M. Mody, Adsorption of an anionic dye from aqueous medium by organoclays: equilibrium modeling, kinetic and thermodynamic exploration, RSC Adv., 2012, 2, 8663.

8 K. O. Amayo, A. Raab, E. M. Krupp and J. Feldmann, Identification of arsenolipids and their degradation products in cod-liver oil, Talanta, 2014, 118, 217-223.

9 M. J. Ruiz-Chancho, M. S. Taleshi, W. Goessler and K. A. Francesconi, A method for screening arsenolipids in fish oils by HPLC-ICPMS, J. Anal. At. Spectrom., 2012, 27, 501-504.

10 A. Rumpler, J. S. Edmonds, M. Katsu, K. B. Jensen, W. Goessler, G. Raber, H. Gunnlaugsdottir and K. A. Francesconi, Arsenic-Containing Long-Chain Fatty
Acids in Cod-Liver Oil: A Result of Biosynthetic Infidelity?, Angew. Chem., Int. Ed., 2008, 47, 2665-2667.

11 E. Schmeisser, W. Goessler, N. Kienzl and K. A. Francesconi, Direct measurement of lipid-soluble arsenic species in biological samples with HPLC-ICPMS, Analyst, 2005, 130, 948.

12 M. S. Taleshi, K. B. Jensen, G. Raber, J. S. Edmonds, H. Gunnlaugsdottir and K. A. Francesconi, Arseniccontaining hydrocarbons: natural compounds in oil from the fish capelin, Mallotus villosus, Chem. Commun., 2008, 4706.

13 G. Raber, S. Khoomrung, M. S. Taleshi, J. S. Edmonds and K. A. Francesconi, Identification of arsenolipids with GC/ MS, Talanta, 2009, 78, 1215-1218.

14 K. O. Amayo, A. Raab, E. M. Krupp, H. Gunnlaugsdottir and J. Feldmann, Novel Identification of Arsenolipids Using Chemical Derivatizations in Conjunction With RP-HPLC-ICPMS/ESMS, Anal. Chem., 2013, 85, 93219327.

15 M. S. Taleshi, G. Raber, J. S. Edmonds, K. B. Jensen and K. A. Francesconi, Arsenolipids in oil from blue whiting Micromesistius poutassou - evidence for arsenic-containing esters, Sci. Rep., 2014, 4, 7492.

16 K. O. Amayo, A. Petursdottir, C. Newcombe, H. Gunnlaugsdottir, A. Raab, E. M. Krupp and J. R. Feldmann, Identification and Quantification of Arsenolipids Using Reversed-Phase HPLC Coupled Simultaneously to High-Resolution ICPMS and HighResolution Electrospray MS Without Species-Specific Standards, Anal. Chem., 2011, 83, 3589-3595.

17 V. Sele, H. Amlund, M. H. G. Berntssen, J. A. Berntsen, K. Skov and J. J. Sloth, Detection of arsenic-containing hydrocarbons in a range of commercial fish oils by GCICPMS analysis, Anal. Bioanal. Chem., 2013, 405, 5179-5190.

18 U. Arroyo-Abad, J. Mattusch, S. Mothes, M. Möder, R. Wennrich, M. P. Elizalde-González and F.-M. Matysik, Detection of arsenic-containing hydrocarbons in canned cod liver tissue, Talanta, 2010, 82, 38-43.

19 S. Lischka, U. Arroyo-Abad, J. Mattusch, A. Kühn and C. Piechotta, The high diversity of arsenolipids in herring fillet (Clupea harengus), Talanta, 2013, 110, 144152.

20 U. Arroyo-Abad, S. Lischka, C. Piechotta, J. Mattusch and T. Reemtsma, Determination and identification of hydrophilic and hydrophobic arsenic species in methanol extract of fresh cod liver by RP-HPLC with simultaneous ICP-MS and ESI-Q-TOF-MS detection, Food Chem., 2013, 141, 3093-3102.

21 V. Sele, J. J. Sloth, B. Holmelid, S. Valdersnes, K. Skov and H. Amlund, Arsenic-containing fatty acids and hydrocarbons in marine oils - determination using reversed-phase HPLC-ICP-MS and HPLC-qTOF-MS, Talanta, 2014, 121, 89-96.

22 A. Raab, C. Newcombe, D. Pitton, R. Ebel and J. Feldmann, Comprehensive Analysis of Lipophilic Arsenic Species in a Brown Alga (Saccharina latissima), Anal. Chem., 2013, 85, 2817-2824. 
23 M. Morita and Y. Shibata, Isolation and identification of arseno-lipid from a brown alga, Undaria pinnatifida (Wakame), Chemosphere, 1988, 17, 1147-1152.

24 S. A. Viczek, K. B. Jensen and K. A. Francesconi, Arseniccontaining phosphatidylcholine: a new group of arsenolipids discovered in Herring Caviar, Angew. Chem., Int. Ed., 2016, 55, 5229-5262.

25 S. Meyer, G. Raber, F. Ebert, L. Leffers, S. M. Muller, T. S. Taleshi, K. A. Francesconi and T. Schwerdtle, In vitro toxicological characterisation of arsenic-containing fatty acids and three of their metabolites, Toxicol. Res., 2015, 4, 1289-1296.

26 S. Meyer, M. Matissek, S. M. Muller, M. S. Taleshi, F. Eert, K. A. Francesconi and T. Schwerdtle, In vitro toxicological characteristion of three arsenic-containing hydrocarbons, Metallomics, 2014, 6, 1023-1033.

27 H. Takeuchi, S. Sekine, K. Kojima and T. Aoyama, The application of medium-chain fatty acids: edible oil with a suppressing effect on body fat accumulation, Asia Pac. J. Clin. Nutr., 2008, 17(Suppl. 1), 320-323. 